\title{
A Pilot Study on Efficacy of Vishakalpa (Shwetra lepa) in Shwetra (Vitiligo)
}

\author{
Research Article
}

\section{Akhilesh Deshmukh1, Nilima Wadnerwar ${ }^{2 *}$, Apurva Gaikwad1}

\author{
1. PG Scholar, 2. Associate Professor,
}

Department of Agadtantra, M.G.A.C.H. \& R.C., Salod (H),

Datta Meghe Institute of Medical Sciences (DU), Wardha, Maharashtra, India.

\begin{abstract}
Shwetra (Vitiligo) is a skin disease which takes longer time to cure. It affects the external beauty of the body causing social stigma, shyness, loss of confidence, fear of comments marital problems, etc. The disease needs repeated shodhana and regular internal and external shaman chikitsa for longer duration. Objectives: To study the efficacy of Vishakalpa (Shwetra lepa) alone in the management of Shwetra and to provide a potent drug for sure and quick relief from Shwetra (vitiligo), this pilot study was carried out. Material and methods: Shwetra lepa was prepared and used as local application in 15 patients having newly diagnosed patches of vitiligo. The changes in shape, size and number of patches and VETI score was assessed before and after treatment. The data was analyzed with the help of parametric and non parametric tests. Results: Though there was no significant change in VETI score, minimal reduction in shape and size of patches, daha and kandu was observed with Shwetra lepa vati. Conclusion: One month study duration for local application of Shwetra lepa vati and sample size was found to be insufficient to prove the efficacy of Shwetra lepa. Hence it is recommended that Shwetra lepa should be used alone for longer period up to 6 to 9 months or it can be used along with repeated shodhana and continuous shamana chikitsa for 2 to 6 months for effective results.
\end{abstract}

Key Words: Shwetra, Vitiligo, Vishakalpa, VETI score, Shwetra lepa vati.

\section{Introduction}

About $1-2 \%$ of the general populations suffer from vitiligo. (1) This disorder is characterized by depigmented or hypo pigmented patches that result from absence or reduction in melanocytes. It starts with small white patch and spread on the other body parts. Treatment includes UV phototherapy, immune mediators and skin camouflage. In mild cases, vitiligo patches can be hidden with makeup or other cosmetic camouflage solutions, de-pigmenting, transplanting melanocytes and sometimes patient has to undergoes surgery. Patients have to take medicines for longer period. Moreover, the treatment is not cost effective. The person suffering from any skin disease, has to face many problems like social stigma, shyness, loss of confidence, fear of comments marital problems, etc.

Acharya Charaka has described Shwetra (Vitiligo) in kushta chikitsa separately. Irregularities in diet, irregularity in daily routine, contraindicated or unsuitable diet, papakarma, beejadosha are some causes behind Kushta and Shwetra. These causes are responsible for vitiation of doshas inside the body. Lack of immune system helps vitiated doshas to move

\section{* Corresponding Author:}

\section{Nilima Wadnerwar}

Associate Professor, Department of Agadtantra, Mahatma Gandhi Ayurved College, Hospital \&

Research Centre, Salod(H), Datta Meghe Institute of Medical Sciences (DU), Wardha.

Email Id: dr.nilima wadnerwar@rediffmail.com through sapta dhatus resulting in Shwetra and Kushta. Acharya Charaka had mentioned special treatment for Shwetra in Chikitsasthana Kushta chikitsa. Treatment should start after purification of body with vamana and virechana with Kakodumbar swarasa along with jiggery. (2) Khadira kwath is the best medicine for Shwetra. Manashiladi lepa is also indicated by Acharya Charaka. (2) Acharya Sushruta has described Bhallataka, Shilajeet, Khadira, Agaru, Tuvaraka in Shwetra after vamana, virechana and raktamokshana. Bakuchi along with Gomutra is one of the popular drugs to treat Shwetra. (3) Shwetrahara vati, Shwetrahara kashaya are some examples of internal medication for Shwetra and Shwetra lepa, Bakuchi lepa are some external applications.

Normal skin either it is white or black, needs uniformity in nature. Any abnormality or alteration in the skin, disturb the normality in life. By seeing alteration many people ask about it which attracts our concentration towards that. Shwetra is the disorder in which white patches are formed on the skin which is definitely disturbing situation for the person. Many marital life or marriages get disturbed due to this disorder. So to treat this disorder, patients spend much more money on the treatment. So many researches were found in which formulations were used along with shodhana chikitsa which found to be more effective compared to other single formulations. Single formulations were used for longer duration up to 9 months. The available contemporary treatments are time consuming and costly. In Rasaratna sammucchaya, Shwetra lepa (4) is mentioned for the treatment of 
Shwetra under the roof of Vishakalpa. There are three shwetra lepa mentioned under Vishakalpa. Out of these three, formulation having ingredients viz. Visha (Vatsanabha-Aconitum ferox Wall.), Bhallataka (Semicarpus anacardium Linn.), Dwipi (ChitrakaPlumbago zeylanica L.), Gunja (Abrus precatorius Linn), Nimba phala (Azadirachta indica A. Juss.) with Nimbu (Citras limon L.) swarasa (Lemon juice) was selected for the study.

Shwetra lepa contains four poisonous herbs viz, Vatsanabha, Bhallataka, Gunja and Chitraka. Visha dravya has fast action in comparison with other drugs. They spread quickly and show immediate effect in the body. Hence, to study the efficacy of Vishakalpa (Shwetra lepa) alone in the management of Shwetra and to provide a potent drug for sure and quick relief from Shwetra (vitiligo), this pilot study was carried out.

\section{Materials and Methods}

After getting IEC approval Ref No. DMIMS(DU)/IEC/2015-16/2011 dated 09/04/2016, the study was started. The raw drugs procured from market were identified and authenticated from Department of Dravyaguna, Mahatma Gandhi Ayurved College, Hospital and Research Centre, Salod(H), Wardha. The study included shodhana (purification) of visha dravya according to classical references, preparation of shwetra lepa and its clinical study.

\section{Shodhana of Vatsnabha (5)}

Two $\mathrm{Kg}$ of small pieces of Vatsanabha (aconitum ferox) roots were taken in a clean piece of cloth and tied it loosely. Potalli (Sac) was completely dipped in seven liters of Gomutra and kept in sunlight on first day. On second day, old Gomutra was replaced with fresh six liters of Gomutra. On third day, same procedure was repeated with three liters of Gomutra. Pieces of Vatsanabha root were taken outside the potalli on fourth day and outer cover was removed and dried in sunlight. $850 \mathrm{gm}$ of purified Vatsanabha root was obtained and fine powder was made. $750 \mathrm{gm}$ of fine powder was obtained for further process.

Fig.1: Shodhana of Vatsanabha

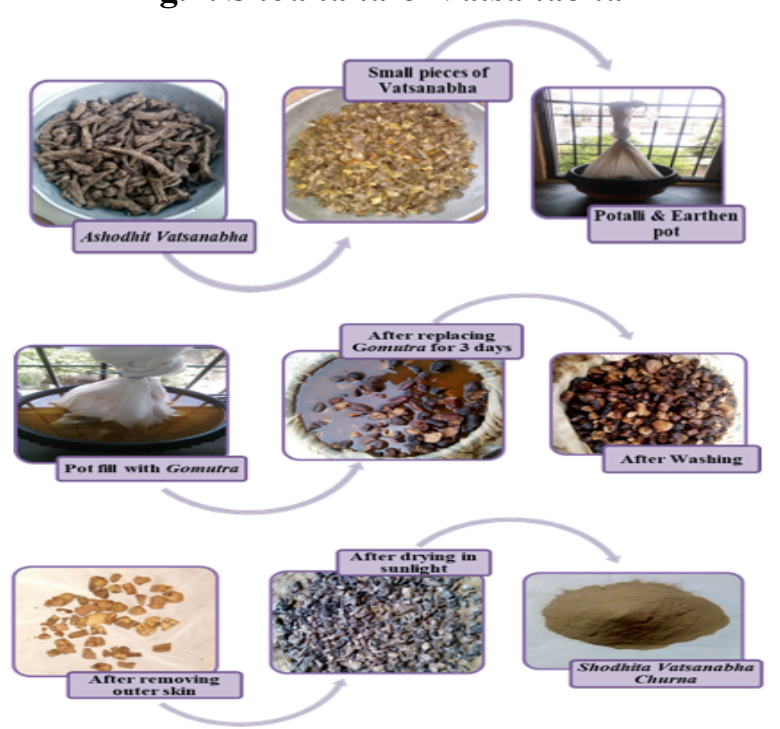

\section{Shodhana of Bhallataka: (6)}

Two Kg of Bhallataka (Semicarpus anacardium) fruits were kept in Ishtika churna (brick powder) after removing crown and were rubbed till brick powder soaked with oil and cover of fruit was peeled off. Bhallataka fruits were washed with hot water to remove Ishtika churna particles. After drying, fine powder was prepared (750 gm).

Fig.2: Shodhana of Bhallataka

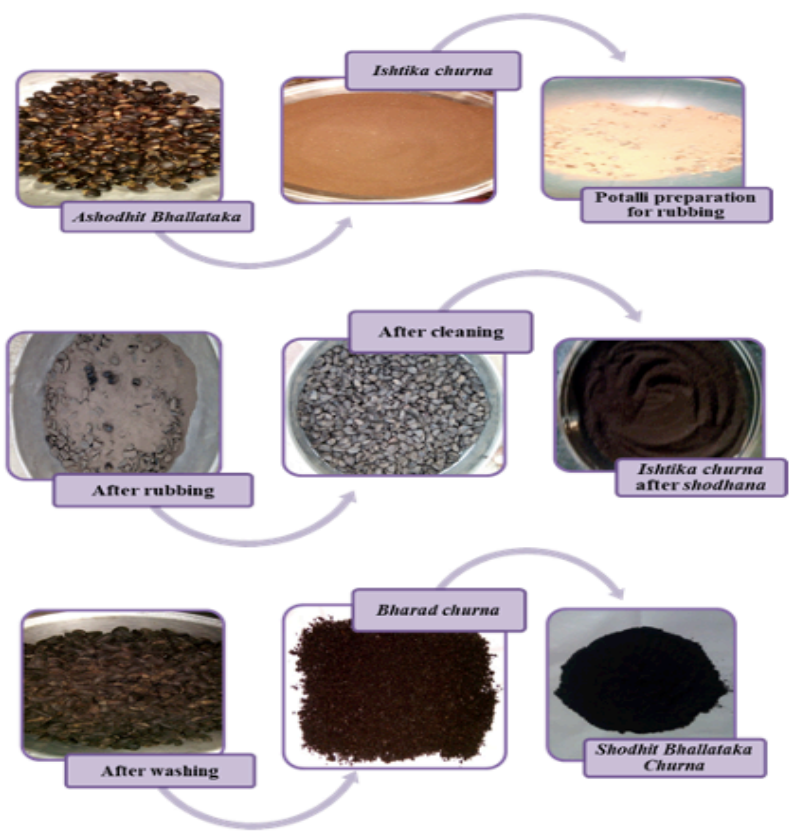

\section{Shodhana of Gunja: (7)}

Two Kg of Gunja (Abrus precatorius) seeds were tied in a two layered cloth and the pottali was kept suspended in six liters of cow milk taken in an earthen pot (dolayantra). The milk was boiled with the Gunja seed pack suspended for 1 Yama (3 hours). After this, the seeds were taken out, washed in hot water, outer cover was removed and cereal thus obtained were dried in sun shade. $900 \mathrm{gm}$ fine powder was obtained for further process.

Fig. 3: Shodhana of Gunia

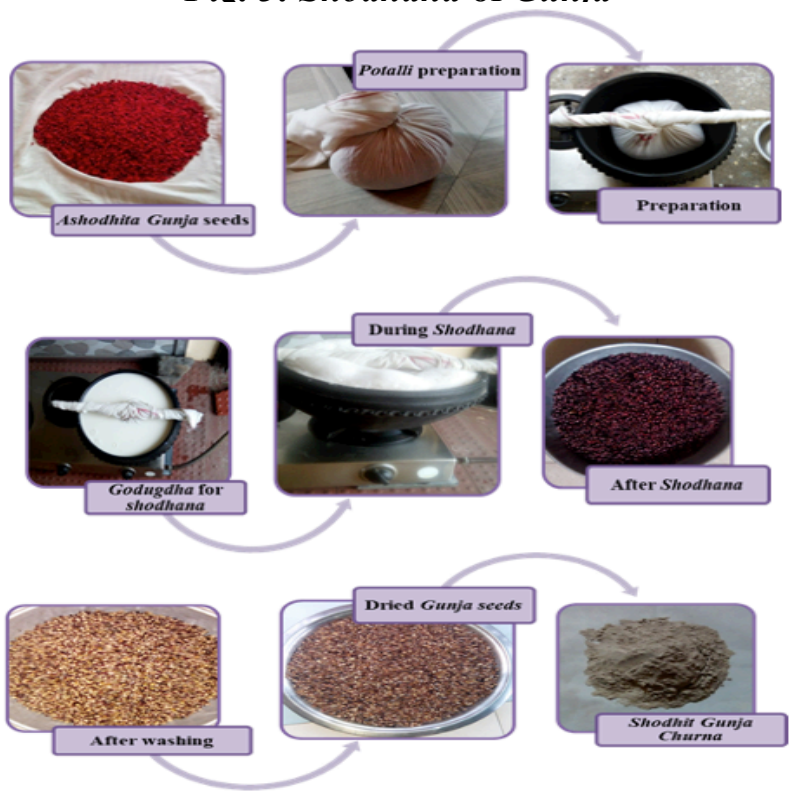




\section{Preparation of Shwetra lepa: (4)}

Chitraka roots and Nimba phala were crushed separately in khalva yantra and made into fine powder. $200 \mathrm{gm}$ of each of the fine powders, Shodhita Vatsanabha, Shodhita Gunja, Shodhita Bhallataka, Chitraka root and Nimba phala were mixed properly (Sample 1).

The application of lepa in powder form along with nimbu swarasa may have problems such as waste of powder, uneven quantity of fresh nimbu swarasa daily and differences in consistency of lepa. Considering these difficulties, it was decided to modify churna used for lepa into lepa vati. $200 \mathrm{gm}$ of each of the fine powders, Shodhita Vatsanabha, Shodhita Gunja, Shodhita Bhallataka, Chitraka root churna and Nimba phala churna were mixed properly and bhavana (trituration) of Nimbu swarasa was given for three days. On first day $3700 \mathrm{ml}$ of Nimbu swarasa was required for bhavana. Second day second bhavana was given with $500 \mathrm{ml}$ of nimbu swarasa and third bhavana was given with $300 \mathrm{ml}$ of nimbu swarasa to nearly maintain the $\mathrm{pH}$ of the lepa vati.

Long sticks of mixture were made and allowed them to dry in shade. After drying two inches small vati was cut into pieces for clinical use (sample 2). Both the samples were subjected to physicochemical analysis and only sample 2 was used for clinical study.

\section{Fig. 3: Preparation of Shwetra lepa}

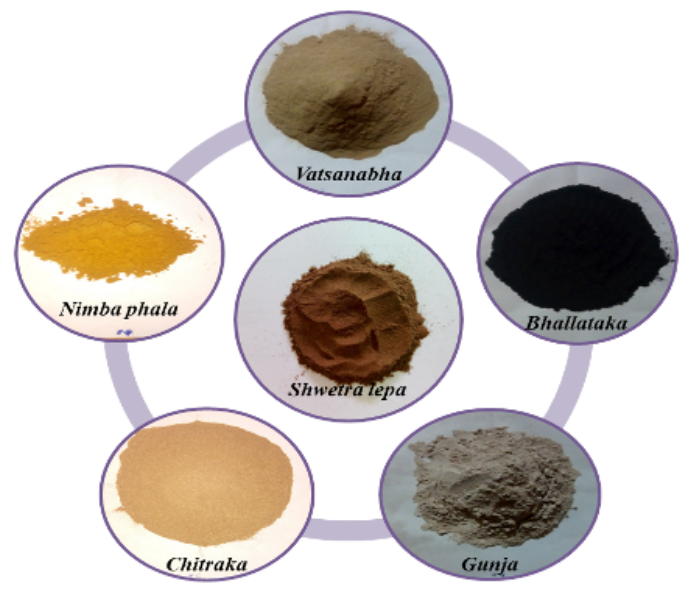

Fig. 4: Preparation of Shwetra lepa vati

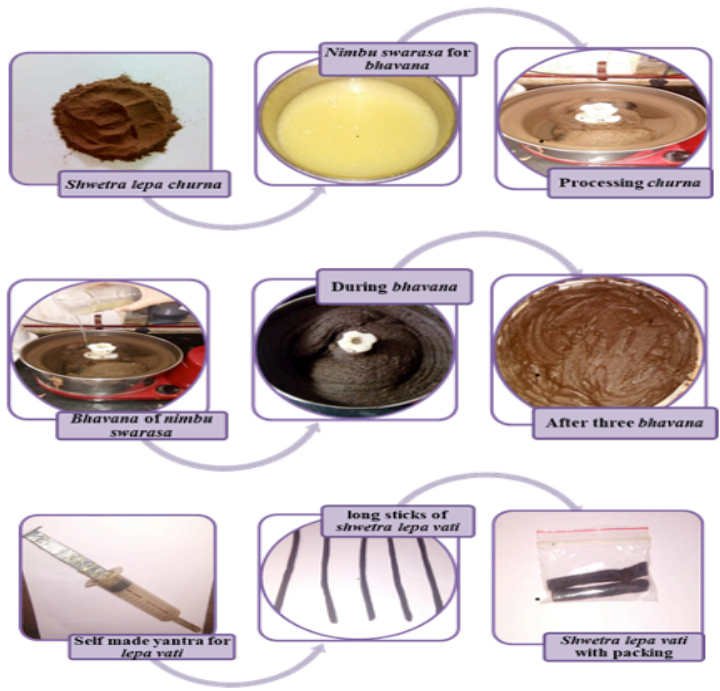

\section{Clinical Study}

Patients of Shwetra were screened and enrolled from Kayachikitsa and Panchakarma O.P.D.; M.G.A.C.H. \& R.C., Salod (H), Wardha as well as specialty camp was arranged on date 11 January 2018. Total 27 patients of Shwetra were screened and after following inclusion and exclusion criteria, 15 patients were selected for study. The consent was received after due consultation with participants and their relatives.

Patients with age group of 20-60 years with newly diagnosed white, thin patch or patches on extremities and trunk and having no discoloration of hair were selected for the study. Patients with Shwetra having combined patches, hairs on patch turns reddish or whitish, old patches more than one year duration, patches near eyes, nose, lips and natural orifices, skin diseases other than shwetra, white patch due to any injury or burn, allergic skin diseases, lesions caused by certain phenolic compounds, due to tight and prolonged pressure by articles of wearing apparel and lesions of neurogenic influences were excluded.

Drug sensitivity test was performed before application of lepa over the white patches. Lepa was applied on calf region and kept for about 10 minutes. The participants having no sensitivity reaction were allowed to apply the lepa twice a day on affected area only by rubbing the Shwetra lepa vati in lemon juice. The participants were asked to wash the affected area after drying the lepa completely without sunlight and fan (at room temperature). The lepa was applied regularly for one month. Follow up was taken after every 7 days during the intervention and 15 days after completion of therapy.

Number of patches, region of patches, discoloration and gradation of patch (by VETI score), and photographs of patches were assessed before and after treatment. The participants were assessed for presence/absence of daha (burning sensation) and kandu (itching) in the patches.

The VETI score (8) is a new system that proposes to measure the extent of vitiligo by a numerical score and combines analysis of extensity and severity of vitiligo and produce a constant and reproducible number like PASI. The percentage of extension involvement $(p)$ evaluates using the rule of nines.

- Stage 0: Normal skin

- Stage1: Hypopigmentation (Including trichrome and homogeneous lighter pigmentation)

- Stage 2: Complete depigmentation with black hair and with peri-follicular pigmentation

- Stage3: Complete depigmentation with black hair and without peri-follicular pigmentation

- Stage 4: Complete depigmentation with compound of white and black hair with / without peri-follicular pigmentation

- Stage 5: Complete depigmentation with significant hair whitening

Notably an area where hair does not exist normally, like the extremities, is very resistant to treatment and placed in grade five. The total body VETI 
Akhilesh Deshmukh et.al., Efficacy of Vishakalpa (Shwetra lepa) in Shwetra (Vitiligo)

is calculated using the following formula that includes contributions from all body regions:

VETI score $=($ Percentage of head involvement $\times$ grade of tensity) 1

$+($ Percentage of trunk involvement $\times$ grade of tensity) 4

$+($ Percentage of upper limbs involvement $\times$ grade of tensity) 2

$+($ Percentage of lower limbs involvement $\times$ grade of tensity) 4

$+($ Percentage of genitalia involvement $\times$ grade of tensity) 0.1

The coefficients reported in this formula are based on percent of skin surface by the rule of nine. Accordingly the coefficient of head is $1(9: 9=1)$, trunk and lower limb is $4(36: 9=4)$, upper limb is $2(18: 9=2)$ and genitalia is almost $0.1(1: 9=0.1)$.

Percentage of involvement: P; Tensity: T

$$
\begin{aligned}
& \text { VETI: }(\mathrm{Ph} \times \mathrm{Th}) 1+(\mathrm{Pt} \times \mathrm{Tt}) 4+(\mathrm{Pu} \times \mathrm{Tu}) 2+(\mathrm{Pl} \times \mathrm{Tl}) 4+ \\
& (\mathrm{Pg} \times \mathrm{Tg}) 0.1 \\
& 5+20+10+20+0.5=55.5
\end{aligned}
$$

The maximum score of VETI is 55.5.

Statistical analysis was done by using descriptive and inferential statistics using chi square test and software used in the analysis were SPSS 22.0 version and Graph Pad Prism 6.0 version and $\mathrm{p}<0.05$ is considered as level of significance.

\section{Observation and Results}

Table No. 1: Physicochemical analysis of selfprepared Shwetra lepa.

\begin{tabular}{|l|l|l|l|}
\hline $\begin{array}{l}\text { Sr. } \\
\text { No. }\end{array}$ & $\begin{array}{l}\text { Analytical } \\
\text { Parameter }\end{array}$ & Sample 1 & Sample 2 \\
\hline 1 & $\begin{array}{l}\text { Loss on Drying at } \\
105^{0} \text { C }\end{array}$ & $5.5 \%$ & $11 \%$ \\
\hline 2 & $\begin{array}{l}\text { Total Ash Value } \\
\text { Acid insoluble Ash } \\
\text { value }\end{array}$ & $11 \%$ & $13 \%$ \\
\hline 3 & $\begin{array}{l}\text { Water soluble } \\
\text { extractive value }\end{array}$ & $8 \%$ & $2.5 \%$ \\
\hline 5 & $\begin{array}{l}\text { Alcohol soluble } \\
\text { extractive value }\end{array}$ & $12 \%$ & $11 \%$ \\
\hline 6 & pH & 5.50 & 3.36 \\
\hline 7 & Particle Size & 80 mesh & 80 mesh \\
\hline
\end{tabular}

Table No. 2: Age wise distribution of patients

\begin{tabular}{|c|c|c|}
$\begin{array}{c}\text { Age group } \\
\text { (yrs) }\end{array}$ & No of patients & $\begin{array}{c}\text { Percentage } \\
\mathbf{( \% )}\end{array}$ \\
\hline $21-30 \mathrm{yrs}$ & 4 & 26.67 \\
\hline $31-40 \mathrm{yrs}$ & 4 & 26.67 \\
$41-50 \mathrm{yrs}$ & 1 & 6.67 \\
\hline $51-60 \mathrm{yrs}$ & 6 & 40 \\
\hline Total & 15 & 100 \\
\hline Mean \pm SD & $\mathbf{4 2 . 2 0} \pm \mathbf{1 4 . 7 3}$ & $\mathbf{( 2 3 - 6 0} \mathbf{y r s})$ \\
\hline
\end{tabular}

Table No. 3: Gender wise distribution of patients

\begin{tabular}{|c|c|c|}
\hline Gender & No of patients & Percentage (\%) \\
\hline Male & 7 & 46.67 \\
\hline Female & 8 & 53.33 \\
\hline Total & $\mathbf{1 5}$ & $\mathbf{1 0 0}$ \\
\hline
\end{tabular}

Table No. 4: Distribution of patients according to number of patches

\begin{tabular}{|c|c|c|}
\hline No of patches & No of patients & $\begin{array}{c}\text { Percentage } \\
(\mathbf{\%})\end{array}$ \\
\hline Up to 3 & 8 & 53.33 \\
\hline 4 to 6 & 5 & 33.33 \\
\hline 7 to 9 & 0 & 0.0 \\
\hline 10 to 12 & 0 & 0.0 \\
\hline 13 to 15 & 2 & 13.33 \\
\hline Total & 15 & 100 \\
\hline Mean \pm SD & $\mathbf{4 . 4 6} \pm \mathbf{4 . 6 4}(\mathbf{1}$ to 15) \\
\hline
\end{tabular}

Table No. 5: Distribution of patients according to region of patch

\begin{tabular}{|c|c|c|} 
Region of patch & No of patients & Percentage (\%) \\
\hline UE & 12 & 80 \\
\hline T & 2 & 13.33 \\
\hline LE & 4 & 26.66 \\
\hline
\end{tabular}

Table No. 6: Distribution of patients according to duration (months)

\begin{tabular}{|c|c|c|}
\hline Duration in months & No of patients & $\begin{array}{c}\text { Percentage } \\
(\mathbf{\%})\end{array}$ \\
\hline 3 to 5 months & 4 & 26.67 \\
\hline 6 to 8 months & 5 & 33.33 \\
\hline 9 to 11 months & 5 & 33.33 \\
\hline 12 to 14 months & 1 & 6.67 \\
\hline Total & 15 & 100 \\
\hline Mean \pm SD & $\mathbf{7 . 4 0} \pm \mathbf{2 . 7 4 . 6 4}(3$ to 14 months) \\
\hline
\end{tabular}

Table No. 7: Distribution of patients according to grade of tensity before and after treatment

\begin{tabular}{|c|c|c|}
\hline Grade of tensity & Before t/t & After t/t \\
\hline 0 & $0(0 \%)$ & $0(0 \%)$ \\
\hline 1 & $1(6.67 \%)$ & $1(6.67 \%)$ \\
\hline 2 & $14(93.33 \%)$ & $14(93.33 \%)$ \\
3 & $0(0 \%)$ & $0(0 \%)$ \\
4 & $0(0 \%)$ & $0(0 \%)$ \\
5 & $0(0 \%)$ & $0(0 \%)$ \\
\hline Total & $\mathbf{1 5}(\mathbf{1 0 0} \%)$ & $\mathbf{1 5}(\mathbf{1 0 0} \%)$ \\
\hline
\end{tabular}

Table No. 8: Distribution of patients according to Percentage of involvement by the rule of Nine

\begin{tabular}{|c|c|c|}
$\begin{array}{c}\text { \%o of } \\
\text { involvement }\end{array}$ & No of patients & Percentage (\%) \\
\hline Up to $2 \%$ & 13 & 86.67 \\
\hline $2.1-4 \%$ & 2 & 13.33 \\
\hline Total & 15 & 100 \\
\hline Mean \pm SD & $\mathbf{0 . 9 6} \pm \mathbf{1 . 0 3}(\mathbf{0 . 2 0 - 4 . 0 0 )}$ \\
\hline
\end{tabular}

Table No. 9: Comparison of VETI score before and after $t / t$

\begin{tabular}{|c|c|c|c|c|}
$\begin{array}{c}\text { VETI } \\
\text { Score }\end{array}$ & Mean & N & $\begin{array}{c}\text { Std. } \\
\text { Deviation }\end{array}$ & $\begin{array}{c}\text { Std. Error } \\
\text { Mean }\end{array}$ \\
\hline Before $\mathrm{t} / \mathrm{t}$ & 5.90 & 15 & 7.52 & 1.94 \\
\hline After $\mathrm{t} / \mathrm{t}$ & 5.90 & 15 & 7.52 & 1.94 \\
\hline
\end{tabular}


International Journal of Ayurvedic Medicine, Vol 11 (4), 747-753

Table No. 10: Distribution of patients according to Grade of Kandu Score before and after treatment Kandu
Score

\begin{tabular}{|c|c|c|}
\hline Score & Before t/t & After t/t \\
\hline 0 & $9(60 \%)$ & $13(86.7 \%)$ \\
\hline 1 & $3(20 \%)$ & $2(13.3 \%)$ \\
\hline 2 & $3(20 \%)$ & $0(0 \%)$ \\
\hline 3 & $0(0 \%)$ & $0(0 \%)$ \\
\hline Total & $15(100 \%)$ & $15(100 \%)$ \\
\hline $\boldsymbol{\chi 2}$-value & $\mathbf{3 . 9 2}, \mathbf{p}-\mathbf{0}$ alue $=\mathbf{0 . 1 4}, \mathbf{N S}, \mathbf{p}>\mathbf{0 . 0 5}$ \\
\hline
\end{tabular}

Table No. 11: Distribution of patients according to Grade of Daha Score before and after treatment

\begin{tabular}{|c|c|c|}
\hline $\begin{array}{c}\text { Daha } \\
\text { Score }\end{array}$ & Before t/t & After t/t \\
\hline 0 & $8(53.3 \%)$ & $12(80 \%)$ \\
\hline 1 & $6(40 \%)$ & $2(13.3 \%)$ \\
\hline 2 & $1(6.7 \%)$ & $1(6.67 \%)$ \\
\hline 3 & $0(0 \%)$ & $0(0 \%)$ \\
\hline Total & $15(100 \%)$ & $15(100 \%)$ \\
\hline $\boldsymbol{2}$-value & $\mathbf{2 . 8 0}, \mathbf{p}$-value $=\mathbf{0 . 2 4}, \mathbf{N S}, \mathbf{p}>\mathbf{0 . 0 5}$ \\
\hline
\end{tabular}

Fig.5: Images of patient
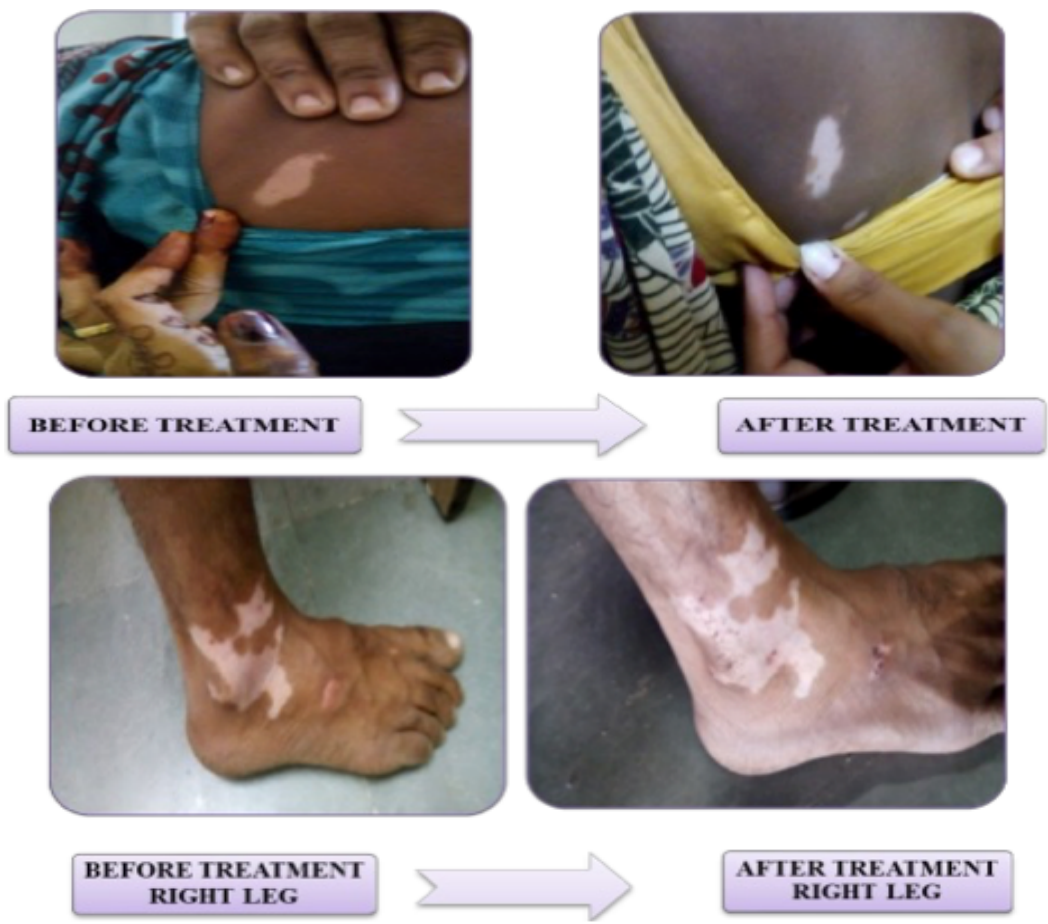

Fig.6: Images of patient

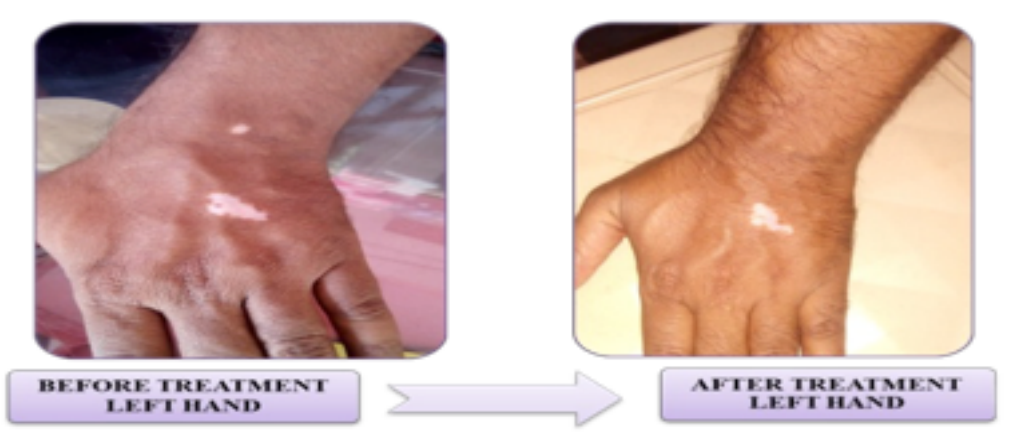

Fig.7: Images of patient
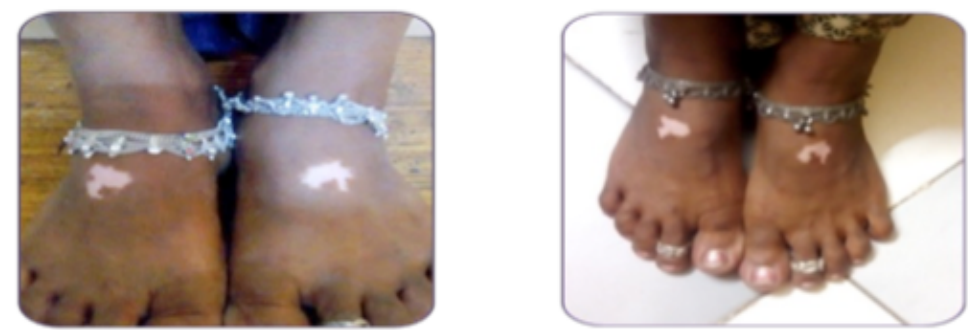

BENORE TREATMENT

APTER TREATMENT 


\section{Discussion}

Vishakalpa indicates the formulations containing poisonous drugs. Here, the word visha is used for all herbal and mineral poisonous drugs and exclusively for Vatsanabha as it is one of the most potent poisons available on earth according to Ayurveda. About seventy nine vishakalpa are mentioned in Rasaratna Samucchaya for various diseases. So many vishakalpa for skin diseases are also mentioned. Three of them are mentioned for Shwetra. Using the properties of visha dravya, it was attempted to find out the efficacy of shwetra lepa alone in shwetra.

After preparation, both the powders were observed to be fine in touch. After processing in nimbu swarasa, Shwetra lepa churna which was pale yellow in colour turns black in colour. Shwetra lepa churna (Sample-1) had characteristic smell whereas Shwetra lepa vati churna with nimbu swaras bhavana (Sample-2) had gomutra gandha (smell).

The loss on drying value obtained indicates moisture content present in the drug. Sample-2 (11\%) contains more moisture in comparison with Sample-1 $(5.5 \%)$ because of processing in liquid media ( $\mathrm{Nimbu}$ swarasa). The total ash value is an indicative of total amount of inorganic material after complete incineration. The total ash value in Sample-1(11\%) and Sample-2 (13\%) were near about same. Acid insoluble ash value indicates that the sample- 2 can be better absorbed in body in comparison with Sample-1 and heavy metal content is absent. The water-soluble extractive value of Sample-1 (8\%) and Sample-2 (1\%) suggested that sugar, acids and inorganic compounds were more in Sample-2 in comparison with Sample-1. Alcohol soluble extractive values of Sample-1 (12\%) and Sample-2 (11\%) indicated that the constituents were soluble in alcohol. $\mathrm{pH}$ value of Sample-1 (5.50) and Sample-2 (3.36) suggested that Sample-2 is more acidic than Sample-1 because of adding nimbu swarasa. The $\mathrm{pH}$ of nimbu swarasa is 2-3 and Sample-2 was 3.36 suggest that the motto behind processing was achieved. Particle size of both the Samples was found to be 80 mesh.

In objective parameters number of white patches, diameter of patches, region of patch, duration, grade of Tensity $\mathrm{T}$, percentage of involvement by rule of nine and VETI score were observed and data was analyzed before and after treatment. In present study, neither new patch was found nor did any patch disappear completely, so the number remained unchanged. Mean $\pm \mathrm{SD}$ value was found to be $4.46 \pm$ 4.64 ( 1 to 15$)$. Diameters of all patches were taken before and after study. In 5 patients, patches were found near tip of fingers and multiple small patches were noted. Hence, it was difficult to measure diameter of each patch. Smallest patch was measured $17 \mathrm{~mm}$ and largest was $175 \mathrm{~mm}$ in diameters. Reduction in the size of patch was observed in only four patients $(3 \mathrm{~mm}$ reduction). In other patients, no change was noted in shape and size of patches after treatment. It is mentioned in Ayurveda texts that patches older than one year was non curable so in present study only those patches were included in study which were newer (up to one year). The youngest patch included in study was 3 month old and oldest was 12 months old. There were five stages of disease tensity (T) (grade 0-5) was studied but only two grades were found in study patients. 6.67 $\%$ (1) patient had Grade 1 tensity (Hypopigmentation) and remaining $93.33 \%$ (14) patients had Grade 2 tensity (Complete depigmentation with black hair and with peri-follicular pigmentation). VETI score was calculated in every patient which was calculated 0.8 as lowest and 28 as highest value. No change in tensity of disease was observed in all the 15 patients. Though there was no significant change in VETI score, minimal reduction in shape and size of patches, daha and kandu was observed.

After application of Shwetra lepa, mild irritation occurred and white spots turned to pinkish colour. After continuous application of lepa, pustules were found which used to rupture automatically in some of the cases. After continuous irruption of skin, dead skin was removed spontaneously and new skin appeared. No adverse reactions were found during the study. By observing these changes in patches, it can be inferred that continuing the same treatment for about 6 to 9 months, skin may regain its natural colour replacing vitiligo patches.

In Ayurveda, Shwetra is treated by application of lepa, shamana chikitsa, shodhana chikitsa, or combined treatment. Patil Kavita et al found Shashilekha Vati significantly effective in a dose of 500 $\mathrm{mg}$ three times a day internally for 49 days.(9) Jadhav HR observed significant changes in size, colour and number of patches in both groups with Apamarga Kshara Yoga Lepa and Apamarga Kshara Yoga Ointment for 8 weeks with $3 \mathrm{~g}$ of Rasayana Churna along with Madhu and Ghrita twice a day as internal medication in both the groups.(10) Dhanik et al reported efficacy of Shvitrahara kashaya and lepa for 6 months in vitiligo with significant pigment regenerating capacity.(11)

The use of traditional Sri Lankan Oil 'The Kakodumbaradi Taila' on Shvitra (Vitiligo) for 120 days proved helpful in complete or partial relieving the signs and symptoms in Shvitra. (12)

Most of the researches suggested that combination of shodhana, internal and external shaman chikitsa is effective treatment for Shwetra. (13-17)

In the present study, one month study duration for local application and sample size was found to be insufficient to prove the efficacy of Shwetra lepa. Hence it is recommended that Shwetra lepa should be used alone for longer period up to 6 to 9 months or it can be used along with repeated shodhana and continuous shamana chikitsa for 2 to 6 months for effective results.

\section{Conclusion}

Preparation of Shwetra lepa vati by processing in Nimbu swarasa gives convenience to patients for the application with same acidic concentration. It can be concluded that though there was no significant change in VETI score, minimal reduction in shape and size of 
patches, daha and kandu was observed with Shwetra lepa vati. One month study duration for local application of Shwetra lepa vati and sample size was found to be insufficient to prove the efficacy of Shwetra lepa. Hence it is recommended that Shwetra lepa should be used alone for longer period up to 6 to 9 months or it can be used along with repeated shodhana and continuous shamana chikitsa for 2 to 6 months for effective results.

\section{References}

1. Nicki R. Colledge, Davidson's principles \& practice of Medicine. 21sted. Lonon; Churchill Livingstone Elsevier; 2010. 1253p

2. Shukla V, Charak samhita of Agnivesha. Reprint. Delhi; Chaukhamba Sanskrit Pratishthan; 2007. 200p.

3. Sharma A R, Sushruta Samhita of Acharya Sushruta. Varanasi; Chaukhamba Surbharti Prakashan; 2010. 252-258p.

4. Mishra S, Rasaratna Samucchaya of Acharya Vagbhata. Varanasi; Chaukhamba Oriantalia; 2011. $661 p$

5. Shashtri L, Yogratnakar, Reprint. Varanasi; Chaukhamba Prakashan, 2007. 165-166p

6. Angadi R, Rasatarangini of Shri. Sadananda Sharma. $1^{\text {st }}$ ed. New Delhi; Chaukhambha Publication; 2015. 482p.

7. Chunekar K, Bhavprakasha Nighantu of Bhavamishra. Reprint. Varanasi; Chaukhamba Bharti Academy. 2013. 339-341p.

8. Feily Amir, Vetiligo Extent Tensity Index (VETI) scores: a new definition, assessment and treatment evaluation criteria in vitiligo, Dermatology Practical \& Conceptual. 2014; 4(4); 18.
9. Patil K, Patil S, Narode S, Duragkar U, Clinical evaluation of Shashilekha vati in the management of Shvitra with special reference to vitiligo. International Journal of Ayurveda and Pharma Research. (2015); 3(8); 46-51.

10. Jadhav H. R, Clinical efficacy of Apamargakshara yoga in the management of Shwetra AYU. 2015; 36 (2); 163-168.

11. Dhanik A, Clinical evaluation of the efficacy of shvitrahara kashay and lepa in shvitra (vitiligo), AYU. 2011; 32 (1); 66-69.

12. Ediriweera E.R.H.S.S. Clinical study on efficacy of the traditional Sri Lankan oil "The Kakodumbaradi Tail" with selected ayurvedic preparations on shvitra (vitiligo). AYU. 2009; 30(3); 225-231.

13. Panigrahi H. K, Efficacy of leech therapy and ayurvedic compound in vitiligo-A QUASI experimental study, International Journal of Research in Ayurveda and Pharmacy. 2012; 3(6); 868-871.

14. Anand N, Sharma U. K, The role of virechana karma with bakuchi churna and avalgujbeejadi lepa in the management of shwetra (vitiligo) International Ayurvedic Medical Journal. 2015; 3(8); 2360-2364.

15. Belge R. S, Belge A. R, Clinical evaluation of the efficacy of Gomutra asava in Shwetra vis-a-vis vitiligo. Journal of Pharmacy and Biological Sciences. 2012; 2(3); 10-13.

16. Ingale P. P, Effect of certain Ayurvedic drugs on Vitiligo (shwetra) in children. International Ayurvedic Medical Journal. 2014; 2(5); 851-857.

17. Ahmed I, Singh C, Purvia R.P, Pharmaco therapeutic evaluation of Putikadi lepa w.s.r. to vitiligo (shwetra) World Journal of Pharmaceutical and Medical Research. 2017; 3(11); 240-250. 